\title{
Interactive comment on "Permafrost distribution in steep slopes in Norway: measurements, statistical modelling and geomorphological implication" by Florence Magnin et al.
}

\section{Anonymous Referee \#2}

Received and published: 27 March 2019

The manuscript presents an important study for a better understanding on how permafrost is distributed within rock walls. It relies on a high number of rock temperature data and the outcomes of the study are significant. The manuscript is rather well written, but sometimes the text is a bit confused and thus not always easy to follow. The results are generally well discussed, and the last section of the discussion presents interesting and original reflections. However, the manuscript contains some issues, the most important one being that the model is not enough clearly explained, as for the model parameters. The way on how the RST data were used to calibrate the model must be much better explained. Some figures must also be improved, because not enough clear or not enough explained. For non Norwegian people it is sometimes dif- 
ficult to follow. I present here after some general comments, and then more specific comments. In the Introduction, a chapter on the different models used hitherto to predict the occurrence of permafrost in rock walls is missing. What is the story of the research in this field? Which models were used? Where ? etc. The method used to predict MARST must be better explained. It's not clear how the authors used the measured MARST to predict MARST. In the equation (1), MARST is predicted from PISR and MAAT only, and I guess the relation between MARST and PISR / MAAT is expressed in the coefficients $b$ and c, but it's not expressively shown. So this section is a bit confused and needs then additional details. The permafrost occurrence is defined when the rock surface temperature is ḯč $0^{\circ} \mathrm{C}$. This is true for permafrost in equilibrium with current climate conditions, but permafrost can be present at depth even with positive surface temperatures, due to thermal offset and thermal inertia. In this case permafrost is not in equilibrium with the current conditions. This must be taken into consideration. Obviously it is, since MAAT is calculated for the period 1981-2010, but this must be better explained. The concepts of "lower limit of permafrost" and of "lowermost observations of the lower altitudinal limit" ( $L A L)$ must be better defined. At this stage the difference is not clear it is not evident to understand why the second was introduced. In the discussion chapter, section 5.3 is very difficult to follow. It contains many descriptive parts that compare permafrost elevation in north and south faces with more gentle slopes in specific locations, which are not always visible on Fig. 11. In the end it is very difficult to capture the main message. I suggest to reorganize the text, to be more systematic in the comparisons, and also more synthetic. Regarding Figure S3, there are huge differences between the outcomes of the two models. This must be addressed in the text. The question of the influence of continentality on the permafrost occurrence and lower limit should be also addressed more largely, and not only for Norway. Some studies (e.g. Sattler et al. 2016 for permafrost in New Zealand) showed that permafrost may reach lower elevations in more humid locations than in continental ones. Regarding the form, in the introduction especially there is a lack of transitions between some sentences. It is often a juxtaposition of sentences, without any link. Ex.

ESurfD

Interactive comment
Printer-friendly version

Discussion paper 
p.1, I.30, P.2, I.13, I.20. The text contains also many typos, especially in the Discussion sections. I noticed some in the specific remarks below, but in the end, I renounced to do it for all the manuscript. So please check them carefully.

Specific comments: P.2, I.14. Why "in the" ? P.2, I.16. Rock fall and rock avalanches are not agents, but processes, or events. p.2. I.22-34. How many of these 800 events triggered from potentially permafrost-affected rock walls ? P.3,I.12. Geologists are also interested in the influence of permafrost on rock wall stability, so choose a more general term than "geomorphologists". p.5, I.2. This kind of sentence should be moved in the state-of-the-art section in the introduction p.5, I.3. Add a reference. p.5, I.8. "therefore" means that from the former line we can directly derive the equation presented. This is not so obvious. Please be more precise. Then I don't understand how the coefficients $a, b$ and $c$ are calculated. p.5, I.9. It is unclear if the way to predict MARST is original in this study of if it has been already proposed in former studies. p.5, I.16. The coma must be moved after "model". p.6, I.14. Unclear to what correspond those 85 MARST points. Due to different years ? p.6, I.24 and following. It's unclear which DEM resolution the authors choose : $1 \mathrm{~m}$ or $10 \mathrm{~m}$ ? p.7, I.11. Fig 4, not 5 p.9 I.18. The "LAL" is not easy to understand. What is the difference with the lower limit of permafrost? Why defining this new concept? p.10, I.3-6. The lower limit of discontinuous permafrost must be better defined (see my general comments). Fig. 10 does not show between $0^{\circ} \mathrm{C}$ isotherm and latitude. In the same section the decrease of the lower limit of permafrost northwards appears to be more pronounced than the decrease of the LAL. How can the authors explain this ? And again, it is really not easy to follow, the difference between the two concepts being not clear. p.10, I.8. Show on a map where the Caledonides are. Then, since most of the rock walls are located in the interior mountain massifs they should also be located in more continental conditions. Thus there is a problem of logic in this sentence. p.10, I.26. Check the syntax. p.11, I.8. . . 2 m AT. First, AT must be spelt out here (the reader may have forgotten the meaning of the acronym). Second, from where comes this $2 \mathrm{~m}$ AT ? I did not find it in the method section. p.11, I.14-15 : Fig. 13 (there is no Fig,. 15) p.12, I.3. Remove the coma after "both". p.12, I.5-8. A bit

\section{ESurfD}

Interactive comment
Printer-friendly version

Discussion paper 
confused. Do not put such long explanations into brackets. p.12, I.26. Both figures 10 and 13 do not show this decreasing elevation of permafrost across continentality.

ESurfD

Fig. 5. Indicate in the caption the significance of the yellow dots. Fig. 9. How can the authors explain the plateau between $62^{\circ} \mathrm{N}$ and $66^{\circ} \mathrm{N}$ ? Fig. 9 and 10 . Please align the grid on the labels of the $Y$ axis. Fig. 11. Please explain somewhere why the threshold 0.5 is used to create the CryWall map. In the caption indicate what show the squares and the yellow circles. Fig. 12. The maps are quite difficult to read. The legend must show the 6 colors present in the map. I suggest to make the differences between the two used models clearer, by having more distinct colors. Same remark for Fig. S3 and S5.

Interactive comment on Earth Surf. Dynam. Discuss., https://doi.org/10.5194/esurf-2018-90, 2019. 